\title{
Implementation of Daily Syndromic Surveillance and Environmental Monitoring at a Large Recreational Event in Australia
}

\author{
Stephanie M Fletcher-Lartey*, Sharon 0’Regan and John Birkett \\ Public Health Unit, South Western Sydney Local Health District, Australia \\ Submission: August 13, 2018; Published: September 19, 2018 \\ *Corresponding author: Stephanie M Fletcher-Lartey, Public Health Unit, South Western Sydney Local Health District, P.O 38 Liverpool, NSW 1871, \\ Australia, Fax: 6128778 0846; Email: Stephanie.Fletcher@health.nsw.gov.au
}

\begin{abstract}
Syndromic surveillance is a strategy that facilitates the identification of public health events at the earliest possible stage during mass gathering events. The South Western Sydney Local Health District Public Health Unit (PHU) collaborated with the 24th Australian Scouts Jamboree 2016 (AJ2016) event organisers to implement daily syndromic surveillance and environmental health monitoring at the event held in January 2016 in south western Sydney, Australia. The event was attended by approximately 11,000 Scouts, $75 \%$ of whom were youths under 14 years of age, with an additional 10,154 guests attending on visitor's day. Based on the duration, the age groups involved and occurrence in the Southern Hemisphere Summer, AJ2016 was classified as a medium to high risk mass gathering event; hence daily syndromic surveillance and environmental health monitoring was implemented.

Pre-event campsite visits were conducted to carryout risk assessment, implement risk management strategies and to provide guidance on the use of daily reporting forms. While the event was generally incident free, a small outbreak of gastrointestinal illness which was thought to be transmitted from person to person was reported among a sub-camp during the second week. The outbreak was effectively contained by the event staff with support from the PHU. The implementation of syndromic surveillance and environmental monitoring during AJ2016 emphasized the importance of public health preparedness in the management of the complexities associated with mass gathering events. This approach was facilitated by strong partnerships between the organisers and the PHssU demonstrating how inter-sectoral collaboration leads to effective delivery of public health actions.
\end{abstract}

\section{Introduction}

Early identification of a significant public health event enables a timely and effective response that can result in the prevention and control of disease spread and meets the requirements of the International Health Regulations (IHR) [1]. Syndromic surveillance is a strategy that facilitates the identification of public health events at the earliest possible stage. The World Health Organization defines syndromic surveillance as "the use of health-related data based on clinical observations rather than laboratory confirmation of diagnoses." Mass gatherings can introduce new and challenging risks to public health systems but can provide an opportunity to strengthen core surveillance and response capacity in keeping with the IHR requirements [1]. A syndromic surveillance approach can identify seasonal trends in emerging and re-emerging infectious diseases and detect disease outbreaks and environmental exposures, that leads to timely public health actions [1]. Adequate planning and preparedness of local public health systems facilitate the management of the complexities associated with mass gathering events (MGEs), including: risk assessment, system enhancement, identification of potential public health risks, preventing or minimizing their occurrence and timely response to public health emergencies [2].
The Australian Scouts Jamboree 2016 (AJ2016) was a mass gathering event that included onsite activities such as abseiling, water sliding, high ropes course, and a water and mud obstacles course, supplemented by offsite activities. The majority (75\% or 8354) of the approximately 11,000 participants from Australia and overseas were Scouts 11 - 14 years of age supported by Leaders 18 years and older (24\%) and Junior Service Leaders 16-18 years of age (1\%). An additional 10,154 guests attended the event's visitor's day, increasing the day's attendance to over 21,000 . The Jamboree site was located in a rural section of the South Western Sydney Local Health District (SWSLHD). This event was considered of public health significance due to the potential health and safety risks associated with having a large number of participants camping in a remote location, subject to weather related events (bush fires and storm surges) and an increased potential for the spread of vector borne, airborne, food- and water-borne infections due to the close proximity of participants. The Public Health Unit (PHU) convened an internal multidisciplinary team including Medical, Environmental Health, Communicable Diseases and Epidemiology staff to conduct a risk analysis of the Jamboree. The Toolbox for Implementation 


\section{Juniper Online Journal of Public Health}

of Surveillance at Mass Gatherings [1], was used to assess the magnitude of the event, duration, the age groups involved and the time of year (Southern Hemisphere Summer), and AJ2016 was classified as a medium to high risk mass gathering event
(Table 1). This report describes the implementation of a daily syndromic surveillance and environmental health monitoring for this event and identifies lessons learned from the event that can inform similar future events (Table 2).

Table 1: Syndromic Surveillance Summary of conditions at AJ2016, January 4-14, 2016.

\begin{tabular}{|c|c|c|c|c|c|c|c|}
\hline & \multicolumn{3}{|c|}{ Male } & \multicolumn{3}{|c|}{ Female } & \multirow[t]{2}{*}{ Overall total } \\
\hline & $\leq 16 \mathrm{yrs}$ & $>16 y r s$ & Tot. Males & $\leq 16 \mathrm{yrs}$ & $>16 y r s$ & Tot. Females & \\
\hline $\begin{array}{l}\text { Acute febrile } \\
\text { illness with rash }\end{array}$ & 0 & 0 & 0 & 0 & 0 & 0 & 0 \\
\hline $\begin{array}{l}\text { Acute respiratory } \\
\text { infection with } \\
\text { fever }\end{array}$ & 0 & 0 & 0 & 1 & 0 & 1 & 1 \\
\hline $\begin{array}{l}\text { Acute viral } \\
\text { hepatitis } \\
\text { (suspected) }\end{array}$ & 0 & 0 & 0 & 0 & 0 & 0 & 0 \\
\hline $\begin{array}{c}\text { Gastrointestinal } \\
\text { illness }\end{array}$ & 24 & 2 & 26 & 1 & 3 & 4 & 30 \\
\hline $\begin{array}{l}\text { Meningitis/ } \\
\text { Encephalitis }\end{array}$ & 0 & 0 & 0 & 0 & 0 & 0 & 0 \\
\hline $\begin{array}{l}\text { Undifferentiated } \\
\text { Fever }\end{array}$ & 0 & 0 & 0 & 0 & 0 & 0 & 0 \\
\hline $\begin{array}{l}\text { Temperature } \\
\text { related illness }\end{array}$ & 2 & 0 & 2 & 0 & 0 & 0 & 2 \\
\hline Death & 0 & 0 & 0 & 0 & 0 & 0 & 0 \\
\hline $\begin{array}{c}\text { Other } \\
\text { Unspecified } \\
\text { Conditions* }\end{array}$ & & & & & & & \\
\hline $\begin{array}{l}1 \text { Mesenteric } \\
\text { denitis }\end{array}$ & 1 & 0 & 1 & 0 & 0 & 0 & 1 \\
\hline
\end{tabular}

Table 2: Syndromic Surveillance Summary of conditions at AJ2016, January 4-14, 2016.

\begin{tabular}{|c|c|c|c|}
\hline Risk Factor Classification & Score Allocation & Event & Score \\
\hline \multirow[t]{5}{*}{ Type of Event } & Classic music concert & 1 & \\
\hline & Family gathering & 2 & \\
\hline & Religious meeting & 3 & \\
\hline & Sporting event & 4 & 4 \\
\hline & Music rock festival & 5 & \\
\hline \multirow[t]{6}{*}{ Number of Participants } & $<2000$ & 1 & \\
\hline & $2001-5000$ & 2 & \\
\hline & $5001-10000$ & 4 & \\
\hline & $10001-50000$ & 8 & 8 \\
\hline & $50001-100000$ & 16 & \\
\hline & $>100000$ & 32 & \\
\hline \multirow[t]{2}{*}{ Type of Participants } & 30-65 families & 1 & \\
\hline & 30-65 sport fans & 2 & \\
\hline \multirow[t]{2}{*}{ Prevalent Age Group } & $12-16$ yrs & 3 & 3 \\
\hline & $16-30$ yrs & 4 & \\
\hline \multirow[t]{4}{*}{$\begin{array}{l}\text { Event Location, Density of } \\
\text { Participants }\end{array}$} & Open fields & 1 & \\
\hline & Stadiums & 2 & \\
\hline & Intramural loose crowd & 3 & \\
\hline & Intramural dense crowd & 4 & 4 \\
\hline Duration of the Event & $<8 \mathrm{~h}$ & 1 & \\
\hline
\end{tabular}




\section{Juniper Online Journal of Public Health}

\begin{tabular}{|c|c|c|c|}
\hline & 8h-16h (whole day) & 2 & \\
\hline & Whole day and night & 3 & \\
\hline & More than 1 day and night & 4 & 4 \\
\hline \multirow[t]{3}{*}{ Type of Lodging } & Outside the event area & 1 & \\
\hline & In the event area - hotels, hostels & 2 & \\
\hline & In the event area - camping & 4 & 4 \\
\hline \multirow[t]{3}{*}{ Type of Meals } & Catering & 2 & \\
\hline & Food vendors & 3 & \\
\hline & Self preparation & 4 & 4 \\
\hline \multirow[t]{3}{*}{ Availability of Alcohol } & Restricted & 1 & 1 \\
\hline & Available out of the venue & 2 & \\
\hline & Available at the venue & 4 & \\
\hline \multirow[t]{3}{*}{ Intravenous Drug Use } & Unlikely & 1 & 1 \\
\hline & Limited & 2 & \\
\hline & Frequent & 4 & \\
\hline \multirow[t]{2}{*}{ Season } & Spring/Autumn & 1 & \\
\hline & Summer/Winter & 2 & 2 \\
\hline \multirow[t]{5}{*}{ Medical Services } & $\begin{array}{l}\text { Dedicated net of clinics and } \\
\text { hospitals in the area + first aid } \\
\text { posts at the venue }\end{array}$ & 1 & 1 \\
\hline & $\begin{array}{l}\text { Dedicated net of hospitals in the } \\
\text { area + first aid posts at the venue }\end{array}$ & 2 & \\
\hline & Dedicated net of clinics at the area & 3 & \\
\hline & Only first aid posts at the venue & 4 & \\
\hline & No dedicated medical facilities & 5 & \\
\hline Total Score & & $\begin{array}{l}\text { Min. } 11 \\
\text { Max.72 }\end{array}$ & 36 \\
\hline
\end{tabular}

\section{Public Health Preparedness and Syndromic Surveillance}

Table 3: Daily Syndromic Surveillance Form. definitions and diagnoses of interest.

\begin{tabular}{|c|c|c|c|c|c|c|}
\hline \multicolumn{7}{|c|}{ Reporting Format for Syndromic Surveillance } \\
\hline State & & & \multicolumn{2}{|c|}{ Report No. } & \multicolumn{2}{|c|}{ ASJ2016_01 } \\
\hline Local Health District & & & \multicolumn{2}{|c|}{ Report date } & \multicolumn{2}{|c|}{ dd/mm/yyyy } \\
\hline Report Completed by & & & \multicolumn{4}{|c|}{ Position } \\
\hline \multicolumn{6}{|c|}{ Section A: Syndromic Surveillance } & \multirow{3}{*}{ Tot. Females } \\
\hline \multirow{2}{*}{$\begin{array}{c}\text { See Appendix } 3 \text { for syndrome defi- } \\
\text { nitions }\end{array}$} & & & Tot. Males & \multicolumn{2}{|c|}{ Female } & \\
\hline & $\leq 16 y r s$ & $>16 y r s$ & & $\leq 16 y r s$ & $>16 y r s$ & \\
\hline \multicolumn{7}{|l|}{ Acute febrile illness with rash } \\
\hline \multicolumn{7}{|l|}{ Acute respiratory infection with fever } \\
\hline \multicolumn{7}{|l|}{ Acute viral hepatitis (suspected) } \\
\hline \multicolumn{7}{|l|}{ Gastrointestinal illness } \\
\hline \multicolumn{7}{|l|}{ Meningitis/ Encephalitis } \\
\hline \multicolumn{7}{|l|}{ Undifferentiated Fever } \\
\hline \multicolumn{7}{|l|}{ Temperature-related illness } \\
\hline \multicolumn{7}{|l|}{ Death } \\
\hline \multicolumn{7}{|l|}{ Other Unspecified Conditions* } \\
\hline 1 & & & & & & \\
\hline
\end{tabular}




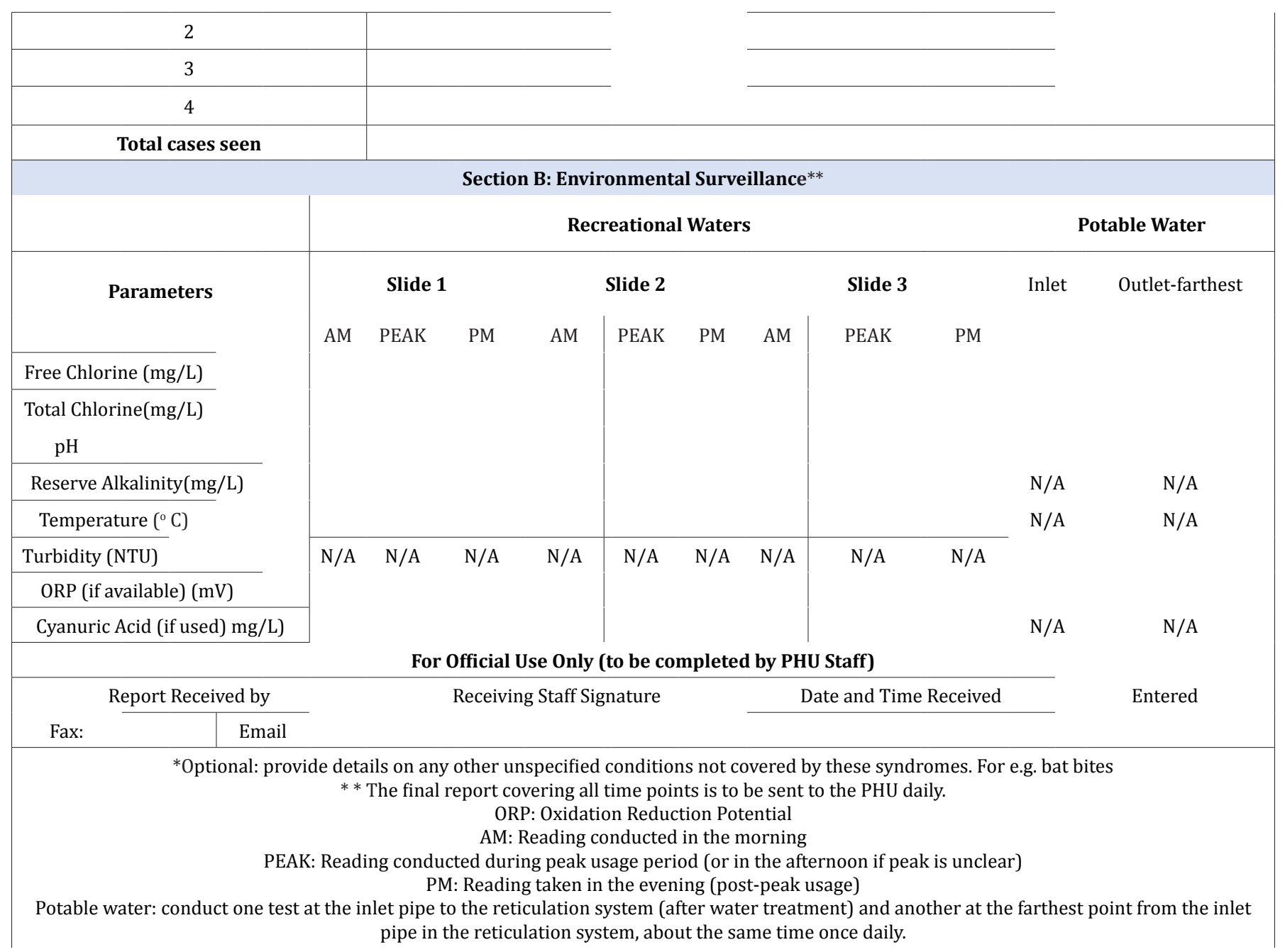

The SWSLHD PHU sought to strengthen its capacity to respond to any public health threats associated with the MGEs [3-5]. Syndromic surveillance was implemented to provide early warning of outbreaks and other events of public health importance, to facilitate immediate action. The following seven core syndromes were monitored under this syndromic surveillance system: acute febrile illness with rash, acute respiratory infection with fever, suspected acute viral hepatitis, gastrointestinal illness, meningitis/encephalitis, undifferentiated fever, temperature-related illness, and death. A daily reporting form (Table 2) and case definitions (Table 3) were developed to guide reporting. Detailed line lists were required for individual patients, only if an outbreak was suspected (i.e., meets case definition for an outbreak). An outbreak can be defined as two or more cases of diarrhoea and/or vomiting clustered together by time, person and place [6]. The onsite medical centre's participation in syndromic surveillance was voluntary; however, the New South Wales Public Health Act [1] stipulates that the coordinating Medical Officer was responsible to notify the Notifiable Conditions Surveillance System of any reportable conditions in keeping with the State's communicable diseases control guidelines. The syndromic surveillance approach was endorsed by the multi-agency emergency management meeting and the event organisers.

\section{Health Risk Assessment and Environmental Health Monitoring}

Pre-event campsite visits were conducted to carryout risk assessment, implement risk management strategies and to provide guidance on the use of daily reporting forms. The PHU was also actively involved in the regional multi-agency emergency management meetings and reviewed various operational and emergency plans for the Jamboree [7]. A Drinking Water Quality Assurance Program (QAP) was required to be lodged with the PHU prior to the event in accordance with the NSW Public Health Act [8]. The QAP was used to assess risks associated with the existing private on-site drinking water supply and augmented water supply from the nearby Cataract Dam for the duration of the event. An additional form to capture water and recreational water quality indicators was also included in the daily reporting requirements. During the event, drinking water quality testing results were reported to the PHU on a daily basis. Drinking water samples were tested daily by two trained on-site volunteers, at a point near the inlet of the drinking water header tank and at the most extreme outlet. Chlorine was automatically dosed into the inlet of the tank by a dosing unit which had been purposefully installed close to the tank. Participants were required to shower before using the water slide and after exiting the challenge valley 
obstacles and activities were staggered over the event so that noone entered the slide after being on a dirty activity. Swimming pool testing was carried out three times daily to the swimming pool attached to the water slide.

\section{Results of Syndromic Surveillance}

Table 4: Syndromes, definitions and diagnoses of interest.

\begin{tabular}{|c|c|c|}
\hline Syndrome & Definition & Diagnoses of Interest \\
\hline 1. Acute Febrile Illness with Rash & $\begin{array}{c}\text { One of: dermatitis, exanthema } \\
\text { Plus: fever (temperature }>38.0 \mathrm{oC} \text { ) } \\
\text { documented or by self-report } \\
\text { Or: clinical diagnosis of measles, rubella, fifth } \\
\text { disease, chickenpox }\end{array}$ & $\begin{array}{l}\text { Measles, rubella, chicken pox, Parvovirus B19 } \\
\text { (Fifth disease), meningococcal disease, Dengue, } \\
\text { Hand, Foot and Mouth Disease }\end{array}$ \\
\hline 2. Acute Respiratory Infection with Fever & $\begin{array}{c}\text { One of: cough, sore throat pharyngitis, } \\
\text { bronchitis, pneumonitis, wheezing, } \\
\text { bronchopneumonia, bronchiolitis, } \\
\text { haemoptysis, shortness of breath, or chest } \\
\text { X-ray showing an infiltrate or mediastinal } \\
\text { abnormality } \\
\text { Plus: fever (temperature > 38.0oC) } \\
\text { documented or by self-report } \\
\text { Influenza Outbreak: Three or more associated } \\
\text { cases of influenza like illness in a } 24 \text { hours } \\
\text { period. }\end{array}$ & Influenza, legionella, MERS-CoV \\
\hline 3. Acute Viral Hepatitis (Suspected) & $\begin{array}{c}\text { One of: jaundice, dark urine } \\
\text { Plus: not chronic or due to drugs/alcohol }\end{array}$ & Acute hepatitis A, B, E \\
\hline 4. Gastrointestinal Illness & $\begin{array}{c}\text { One of: diarrhoea, loose stools, dysentery, } \\
\text { gastroenteritis with vomiting, abdominal pain } \\
\text { (+/- fever, +/- blood, +/- a gastrointestinal } \\
\text { cause of the symptom). } \\
\text { Outbreak: Two or more associated cases of } \\
\text { diarrhoea and/or vomiting in a } 24 \text { hours } \\
\text { period (may be associated with a common } \\
\text { source. For e.g. a suspected food). }\end{array}$ & $\begin{array}{c}\text { Food related illness including: ETEC, Salmonella, } \\
\text { Shigella, Yersinia, Campylobacter, norovirus, } \\
\text { Cryptosporidium, Giardia }\end{array}$ \\
\hline 5. Meningitis/ Encephalitis & $\begin{array}{c}\text { One of: meningitis, encephalitis } \\
\text { Or } \\
\text { One of: encephalopathy, altered mental } \\
\text { status, confusion, delirium, change in level of } \\
\text { consciousness, disorientation or elevated WBC } \\
\text { or protein in CSF } \\
\text { Includes: headache with fever, seizure with } \\
\text { fever } \\
\text { Plus: no underlying cause for the symptoms } \\
\text { recorded unless accompanied by fever }\end{array}$ & $\begin{array}{c}\text { Meningococcal meningitis, viral meningitis, other } \\
\text { viral encephalitidies }\end{array}$ \\
\hline 6. Undifferentiated Fever & $\begin{array}{l}\text { Fever (temperature }>38.0 \mathrm{oC} \text { ) documented or } \\
\text { by self-report, } \\
\text { Excludes: the presence of rash or respiratory } \\
\text { symptoms. }\end{array}$ & $\begin{array}{l}\text { Typhoid, Dengue, Yellow Fever, VHF, Malaria, } \\
\text { other Arboviral infections }\end{array}$ \\
\hline 7. Temperature Related Illness & $\begin{array}{l}\text { Dehydration: due to heat } \\
\text { Heat cramps: muscle pains or spasms (usually } \\
\text { abdomen, arms or legs) } \\
\text { Heat exhaustion: includes heavy sweating, } \\
\text { paleness, muscle cramps, tiredness, weakness, } \\
\text { dizziness, headache, nausea or vomiting, } \\
\text { fainting } \\
\text { Skin may be cool and moist; pulse rate will be } \\
\text { fast and weak; and breathing will be fast and } \\
\text { shallow. } \\
\text { Heat stroke: includes extremely high body } \\
\text { temperature (above } 40^{\circ} \mathrm{C}, \text { orally), red, hot, } \\
\text { and dry skin (no sweating), rapid, strong } \\
\text { pulse, throbbing headache, dizziness, nausea, } \\
\text { confusion, unconsciousness }\end{array}$ & Heat cramps, heat exhaustion, heat stroke \\
\hline 8. Death (All Causes) & $\begin{array}{l}\text { Any sudden death from causes of public health } \\
\text { interest }\end{array}$ & Meningococcal disease, septicaemia, VHF, Malaria \\
\hline
\end{tabular}




\section{Juniper Online Journal of Public Health}

Syndromic surveillance reports were submitted by email daily from January 3 to 15, 2016 using the template provided. High rainfall at the beginning of the event and cooler conditions kept the Jamboree generally incident free with very few heat related illness reported. A total of 34 syndromic cases were reported over the period (Table 4). An increase in the number of gastrointestinal illnesses was identified on January 7. The 30 cases, including three leaders and 27 campers, were clustered amongst various groups within one sub-camp that hosted approximately 500-650 participants; with the index case having onset on January 6, 2016.

The cases were predominantly males 16 years or younger, reported vomiting, nausea and diarrhoea symptoms and were treated at the onsite medical centre between January 6 to 11 (Figure 1). Three clinical samples including one stool and two vomitus samples were obtained by onsite medical staff and sent to local pathology services tested by enteric PCR. Both vomitus samples tested positive for Human Adenovirus (sub-group: F-G); one of which was co-infected with Salmonella spp. The stool sample tested positive for norovirus G11. The last three cases had onset on January 11. There was no environmental specimen or food specimen available for testing. However, the epidemiological evidence suggests that the gastrointestinal outbreak was caused by person to person transmission. Once an outbreak was detected, onsite medical staff in consultation with the PHU instituted infection control measures including isolation of cases, cohorting of affected sub-camp sites including quarantining of toilets, implementing enhanced hygiene measures, distribution of hand sanitisers to camp sites and procedures to prevent infected persons from participating in recreational activities.

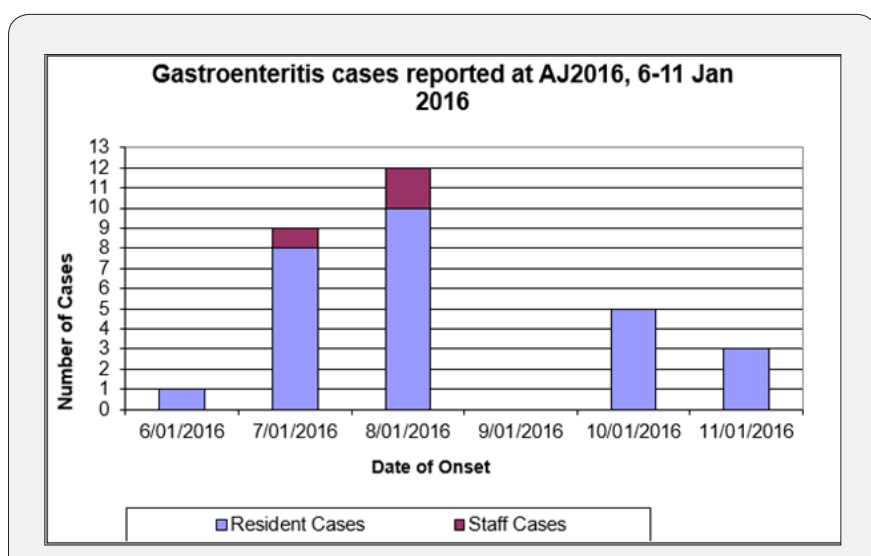

Figure 1.

\section{Results of Environmental Health Monitoring}

Generally, water quality indicators reported daily for the water supply and swimming pool systems were in compliance with NSW Health guidelines. However, several limitations were identified:

a. No automated chlorination of water held in the drinking water tank during normal operations. Scouts were investigating an upgrade to their chlorine dosing system;

b. Poor compliance with monthly microbiological testing requirements for drinking water prior to the event was insufficient to provide a historical trend of the microbiological quality of the water. More frequent testing was recommended to ensure that the drinking water was fit for use at all times.

c. Testing of the swimming pool during the Jamboree was carried out by on-site staff using test strips which are deemed inadequate under the Public Health Regulation. A photometer was required.

d. High rainfall on several days of the event resulted in the closure of Challenge Valley for several days and an assessment of the course was not possible during the site visit. However, site staff confirmed that hand wash stations were supplied at watesr obstacles and that mandatory showering at the end of the course was enforced, to minimise risks to participants.

\section{Feedback from Event Organisers}

The PHU organised debriefing with three representatives from the event organisers in order to share experiences and lessons learned after the event. The organisers felt that having a direct liaison in the PHU was helpful and the 'syndromic surveillance was a good effort, was worth doing and facilitated transparency between the event organisers and the PHU.' The daily reporting was managed by senior medical staff but they felt that in future this could be delegated to less senior staff. The availability of a team of more than 32 experienced clinical volunteers helped to prevent any major medical emergencies. Additional monitoring support from full time site staff helped to address limitations in high workload for some event volunteers.

\section{Discussion}

The classification of AJ2016 as a medium/high risk mass gathering event justified the development and implementation of a syndromic surveillance and environmental monitoring strategy. The implementation of this strategy was seamlessly integrated into routine public health surveillance and resulted in a heightened level of awareness and preparedness that facilitated health staff to respond to potential threats at this event. The early detection of a gastroenteritis outbreak and water treatment failures resulted in effective prevention of major health threats. This collaborative approach to public health preparedness and response has provided further evidence for the application of health surveillance systems at MGEs.

A shared understanding about daily monitoring and a liaison at both the event and the PHU facilitated to effective communication. The planning, risk analysis and implementation of a syndromic surveillance and environmental monitoring strategy for this MGE, has provided important new learnings to inform preparedness strategies for similar events. This report is limited in that it does not include information on hospitalisations or other incidents. While this type of surveillance approach has 


\section{Juniper Online Journal of Public Health}

been used repeatedly, there were previously no standardised protocols for implementation, the types of disease syndromes that should be reported, and was usually discretionary in many jurisdictions [1]. The implementation of the revised IHR 2007 provides a universal template to guide the development of core capacity for disease surveillance and response [1,2]. However, challenges still remain with the sensitivity and specificity of syndromic cases definitions in the early detection of some diseases, and as a result laboratory and hospital active surveillance must be conducted alongside syndromic approach [9]. The system requires adequate technology, skilled personnel and communication resources to facilitate the timely transmission and analysis of data to inform action. As such, careful planning and collaboration amongst stakeholder is necessary for an organized and effective public health response $[9,2]$. Patterson suggested that the success of such an approach is largely dependent on factors such as the simplicity of the system; political will and support from all tiers of government; clarity around roles and responsibilities of different stakeholders; timely and constructive feedback to operational staff on data quality and suitability; standardisation of case definitions; systematic connection between existing health information systems and the syndromic data collection tools; and availability and access to technical, clinical and epidemiological support [3]. It also requires a balance between strengthening the proven traditional surveillance approaches and syndromic surveillance systems $[10,11]$.

The combination of syndromic surveillance and environmental health monitoring was utilised for the first time by the SWSLHD PHU for the AJ2016 event. Their application reinforced the advantage of implementing early warning systems for mass gathering events. The implementation of the protocol emphasized the importance of public health preparedness in the management of the complexities associated with mass gathering events and demonstrated that inter-sectoral collaboration between the organisers and the PHU lead to effective delivery of public health actions

\section{References}

1. New IHR (2005) 58th World Health Assembly 2005. Revision of the International Health Regulations.

2. World Health Organization (2008) Communicable disease alert and response for mass gatherings: Key considerations.

3. Institute of Medicine (US) (2007) Forum on Microbial Threats. Global Infectious Disease Surveillance and Detection: Assessing the Challenges Finding Solutions, Workshop Summary. Washington (DC): National Academies Press (US) Summary and Assessment.

4. Zielinski A, Pawlak BJ (2011) React project: Toolbox for implementation of surveillance at mass gatherings. WP 4: Surveillance during mass gatherings.

5. Australian Government, The Department of Health (2010) Guidelines for the Public Health Management of Gastroenteritis Outbreaks due to Noravirus or Suspected Viral Agents in Australia.

6. Environmental Health Branch, NSW Ministry of Health (2014) Drinking water Quality: Private Water Supplies.

7. May Larissa, JeanPaul Chretien, Julie A Pavlin (2009) Beyond traditional surveillance: applying syndromic surveillance to developing settingsopportunities and challenges. BMC Public Health 9(1): 1.

8. New IHR 2005: 58th World Health Assembly 2005. Revision of the International Health Regulations.

9. Mandl KD, Overhage JM, Wagner MM, Lober WB, Sebastiani P, et al (2004) Implementing Syndromic Surveillance: A Practical Guide Informed by the Early Experience. Journal of the American Medical Informatics Association: JAMIA 11(2): 141-150.

10. Paterson BJ, Kool JL, Durrheim DN, Pavlin B (2012) Sustaining surveillance: Evaluating syndromic surveillance in the Pacific. Global Public Health 7(7): 682-694.

11. Uscher Pines L, Farrell CL, Babin SM, Cattani J, Gaydos CA, et al. (2009) Framework for the development of response protocols for public health syndromic surveillance systems: Case studies of 8 US states. Disaster Medicine and Public Health Preparedness 3(S1): S29-S36.

\section{Your next submission with Juniper Publishers will reach you the below assets}

